\title{
Development of New Standardized Package System Interfacing with GMA Pallet for Imported Mangos to the United States
}

\author{
Sher Paul Singh \\ Michigan State University \\ singh@msu.edu \\ Koushik Saha \\ California Polytechnic State University \\ ksaha@calpoly.edu
}

\author{
Vanee Chonhenchob \\ Kasetsart University \\ vanee.c@ku.ac.th \\ Jay Singh \\ California Polytechnic State University \\ jasingh@calpoly.edu
}

\begin{abstract}
This study was conducted in response to the National Mango Board (NMB) and United States Department of Agriculture (USDA) in development of a container for the "Common Packaging Footprint for Mangos." This paper presents the development process for a new corrugated paperboard tray that allows the shipment of an approximate minimum weight of $4 \mathrm{~kg}$ of fresh mangos from various countries in Central and South America imported to the U.S. The mango trays currently being used by packing houses in Central and South America were evaluated. This study identified critical design elements which were used to develop a standardized corrugated tray for mangos. In addition, a survey of the retailers and buyers associated with purchasing mango trays in palletized loads in United States was conducted to assess the impact of the proposed tray design on the mango industry. The results indicated that a 14 down common footprint tray did not "best" meet the $40 \times 48$ Grocery Manufacturers Association (GMA) pallet size. It was capable of holding slightly less than the required $4 \mathrm{~kg}$ of mangos and the cooling efficiency was compromised. The two new proposed designs of 12 down and 15 down trays were capable of holding 5 and $3.75 \mathrm{~kg}$ of mangos, without affecting current pre-cooling efficiencies during post-harvest processing of the fruit. The survey results further indicated that the retailers are willing to consider a tray design which can hold more than $4 \mathrm{~kg} /$ tray, and among the two designs, prefer the proposed 12 down mango tray design.
\end{abstract}

Key Words: Corrugated Tray, Common Footprint, Standardized Package, GMA Pallet, Mango 


\subsection{INTRODUCTION}

This study was conducted in response to the Request for Proposal (RFP) titled "Common Packaging Foot Print for Mangos" provided by the U.S. National Mango Board (NMB). The NMB is a national promotion and research organization supported by assessments from both domestic and imported mangos with oversight by the U.S. Department of Agriculture (USDA). There was a need to develop a new corrugated paperboard tray that allows the shipment of an approximate minimum weight of $4 \mathrm{~kg}$ of fresh mangos from various countries in Central and South America imported to the U.S. The $4 \mathrm{~kg}$ has been an accepted standard for the trade of mangos between various nations supplying the fruit and United States for over five decades. However once imported, into the United States, the mangos are identified with individual product look-up (PLU) codes such as 4051, and are sold by count. Therefore the economic transactions between a grower/shipper and importer are based on total weight based on individual trays meeting the minimum $4 \mathrm{~kg} /$ tray, the ultimate sale to consumer is dependent on the price established by the retailer per count based on quality of fruit displayed.

Originally from India, mangos imported to the United States predominantly come from Mexico, and Central and South America countries. According to the U.S. Census Bureau's Foreign Trade Statistics, import volumes are approaching 300 million metric tons and less than $1 \%$ comes from countries outside the Americas. The main import country is Mexico accounting for nearly $63 \%$ of the mango import volume in the last three years. In the same period, Brazil, Ecuador, Guatemala, Haiti, and Peru accounted for nearly $36 \%$ of the remaining imports. The availability of mangos per capita has increased from 1.88 to 2.11 from 2005 to 2009 respectively. It is therefore a fast growing category in terms of fresh produce.

Currently a wide range of different sizes and configurations of packaging (containers) are used to ship and sell fresh mangos. Each of these configurations offers a different degree of satisfaction to the customer (buyer at a retailer, wholesaler or distributor) and consumer (individuals buying mangos at the store level) in terms of their primary functions of containment, protection, utility and communication. With the exception of WalMart, the leading user of reusable plastic crates in North America for fresh produce, the vast majority of importers rely on a single use paperboard corrugated tray having venting or die cut air flow configurations to allow cooling, and printing on the outside to provide identification and marketing, in an open top display of fruit on the shelf. The mango producing countries and United States (US) importers and retailers have for several decades conducted trade based on a tray with a $4 \mathrm{~kg}$ fixed weight quantity. This study was aimed to design a 14-15 down $(4 \mathrm{~kg})$ tray for mangos that fit a standard $40 \times 48$ inch footprint sized wood based Grocery Manufacturers Association (GMA) pallet. In order for mangos to flow through the US fresh produce logistical supply chain, they have to do so on the standard GMA footprint. In addition to moving to a new pallet footprint it was desired that the new tray does not degrade existing attributes such as cost, strength, cooling rates, shipping density, and protective qualities. The new common footprint trays were designed and evaluated based on lab tests and surveys with retailer buyers to evaluate the above attributes as compared to existing methods.

A standardized package system that fits a GMA pallet footprint and provides better strength was developed in this study. The new design showed less damage to fruit based on lab simulated vibra- 
tion tests, had higher strength based on compression strength tests and better acceptance based on a survey with retailers (buyers) or customers of the fruit.

\subsection{METHODOLOGY}

\subsection{Review of mango packing houses and current mango package system}

Preliminary study was conducted to investigate what a 15 down footprint could hold with an approximate 18 high stack requirement with mango fruit being imported to the United States. This study was done at Michigan State University in the first phase of this project. Over thirty different designs of mango trays were reviewed for design differences, vent holes and stacking capabilities.

In these previous studies, the mango packing operations in Mexico and Guatemala were reviewed [1]. In the present study, a total of 6 mango packing houses were visited in Brazil and Peru to further understand the needs of the post-harvest and packing processes. Mango packing houses visited in Brazil and Peru were as follows:

1. Upa Agricola, Casa Nova, Brazil

2. Agrobrás, Casa Nova, Brazil

3. AM Export, Petrolina, Brazil

4. Distribuidora Internacional, Tambogrande, Piura, Peru

5. Sunshine Export, Tambogrande ,Piura, Peru

6. Biofruit, Tambogrande ,Piura, Peru

In addition, TRUPAL which is the largest corrugated manufacturer in Peru, which also is the largest producer of maximum trays for export to USA, Europe and South America, was visited.

Information about postharvest technology of mangos is available in literatures [2, 3] however there is limited information for the cultivars from Central and South America. Post-harvest operations of mangos in Brazil and Peru were investigated in this study. Mango trays currently being used by packing houses in Brazil and Peru for exporting to the United States were evaluated. Critical design elements which were used to develop a standardized corrugated tray for mangos were identified. The new design was to use the same or less amount of total corrugated board, and be adaptable to box erecting equipment used in these countries.

According to the data reviewed by inspecting the boxes currently being used and visiting the packaging houses in the present study and the previous studies in Mexico and Guatemala [1], new standardized package system for mangos were developed. The following critical steps were followed in this study:

1. Identify the various types of packaging currently used by exporters, importers, wholesalers and retailers for mangos

2. Identify the challenges imposed by major and small retailers for distribution and sales of mangos in the United States

3. Develop criteria for new packaging method that meets the standardization and retail objectives

4. Design new packaging method based on design principles based on input from the customer that is the buyer of this product, that including simplicity, cost, functionality and sustainability, and maintaining quality attributes of the mango fruit

5. Test and compare performance of existing and 
new packaging methods (e.g. compression strength, pre-cooling)

6. Modify and redesign if needed for improving performance of new standardized package system

\subsection{Structural performance}

The new designed boxes fabricated at Michigan State University were compared with the existing boxes for dynamic performance testing (i.e. pre-cooling, vibration test) and stack performance testing (compression test). Our previous studies showed the results of the imported boxes from Mexico and Guatemala [1]. In the present study, the boxes currently being used from Brazil and Peru were compared with the new designs.

Pre-cooling characteristics of the package systems were determined according to the pre-cooling test [2]. Mango temperatures were monitored during the cooling process. For the vibration test, the pre-cooled mangos $\left(4^{\circ} \mathrm{C}, 80 \% \mathrm{RH}\right)$ were filled in the imported boxes from Brazil and Peru and stacked 16 layers high on a pallet. Vibration tests were performed for $60 \mathrm{~min}$ in accordance with ASTM D4728 to evaluate the protective performance of the boxes during shipment [2]. The acceleration amplitude was set at $0.52 \mathrm{G}$ in accordance with ASTM D4169.

Compression strength tests were performed according ASTM D642 to evaluate stack performance using a compression tester Model 152-30K (Lansmont, Inc., Monterey, USA) [3]. Mangos were observed after 24 and 48 hours for permanent deformation, scuffing and bruising. Each type of box was column stacked 3 high.

The data from these tests was used to show that the new design did not cause more bruising to the fruit after the vibration tests. The individual compression strength of the paperboard trays showed the comparison in strength for stacking and shipping. [1]

\subsection{Survey for the new mango package system}

In terms of acceptability of new design by the customers of mangos in the United States that includes wholesalers, retailers, distributors, and club stores. A survey of the retailers and buyers associated with purchasing mango trays in palletized loads, to assess the impact of the proposed tray design on the mango industry were conducted in this study. A total of 88 professional buyers in over 25 major national retailers were contacted in a personal interview using the existing and new package designs created in this study. These included major retailers in North America, for examples Costco, WalMart, Wegmans, Albertsons, Safeway, Krogers, Fresh and Easy and Meijers.

The survey consisted of four specific questions that could impact the transition from the current practice of non-standardized trays that are sized to fit a wood pallet, based on shipping efficiencies to meet the $4 \mathrm{~kg} /$ tray requirement. Simply stated, every grower and shipper tried to fit more trays in a trailer or inter-modal container as the primary and most significant objective. The four questions that were critical to implement the transition to a new tray design with a possibility of different weight per tray and pre-cooling efficiencies to meet a GMA pallet foot-print are listed below.

1. Would you prefer mangos shipped on a standard GMA $(40 \times 48$ inch $)$ pallet?

2. Will you consider the weight per tray of fruit in a new tray other than $4 \mathrm{~kg}$ ? 
3. In the new design, the 12 down will use less corrugated, provide faster pre-cooling, deliver more fruit per shipment, and be more stable than a 15 down option. However the 12 down will have approximately $5 \mathrm{~kg}$ or at least $10 \mathrm{lb}$. of fruit and the 15 down will have $3.75 \mathrm{~kg}$. Please rank your preference of a 12 down or 15 down tray. 1 is most favorable and 5 is least favorable.
1. 12 down $(1,2,3,4,5)$
2. 15 down $(1,2,3,4,5)$
3. Will prefer either

4. Do you want to make any changes in the pallet or tray size?

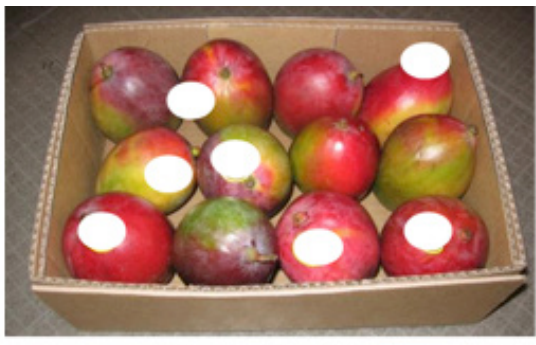

12 count, $3.25 \mathrm{Kg}$

\subsection{RESULTS AND DISCUSSION}

\subsection{Preliminary investigation findings}

In a preliminary study, conducted in the US market, mango fruit being imported to the U.S. was predominately packed in a 15 down footprint with an approximate 18 high stack requirement (Figure 1). It was interesting to note that when larger size fruit is being imported it results in a low pack density in the tray, and sometimes may not meet the $4 \mathrm{~kg} /$ tray requirement in a 5 and 7 fruits/tray configuration. As a result some trays when fully packed will result in being slightly under the $4 \mathrm{~kg}$ requirement. Smaller size fruit on the other hand with varieties such as Ataulfo and Tommy Atkins result in higher pack density and trays carrying more fruit in the 12 count per tray and higher.

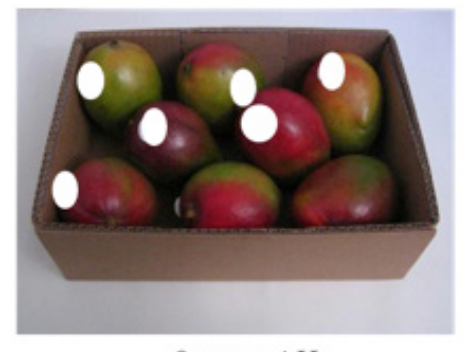

8 count, $4 \mathrm{Kg}$

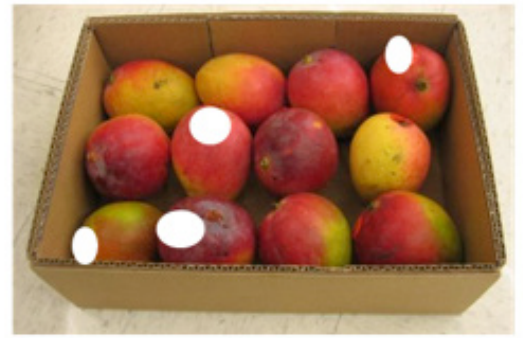

12 count, $3.95 \mathrm{Kg}$

Figure 1. Investigation of 15-down footprint trays for mangos imported to the United States

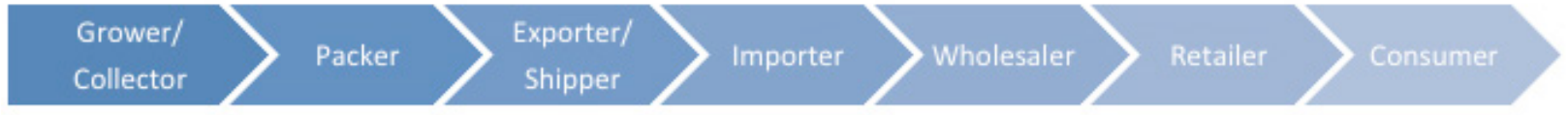

Figure 2. Mango supply chain in Brazil and Peru imported to the United States 


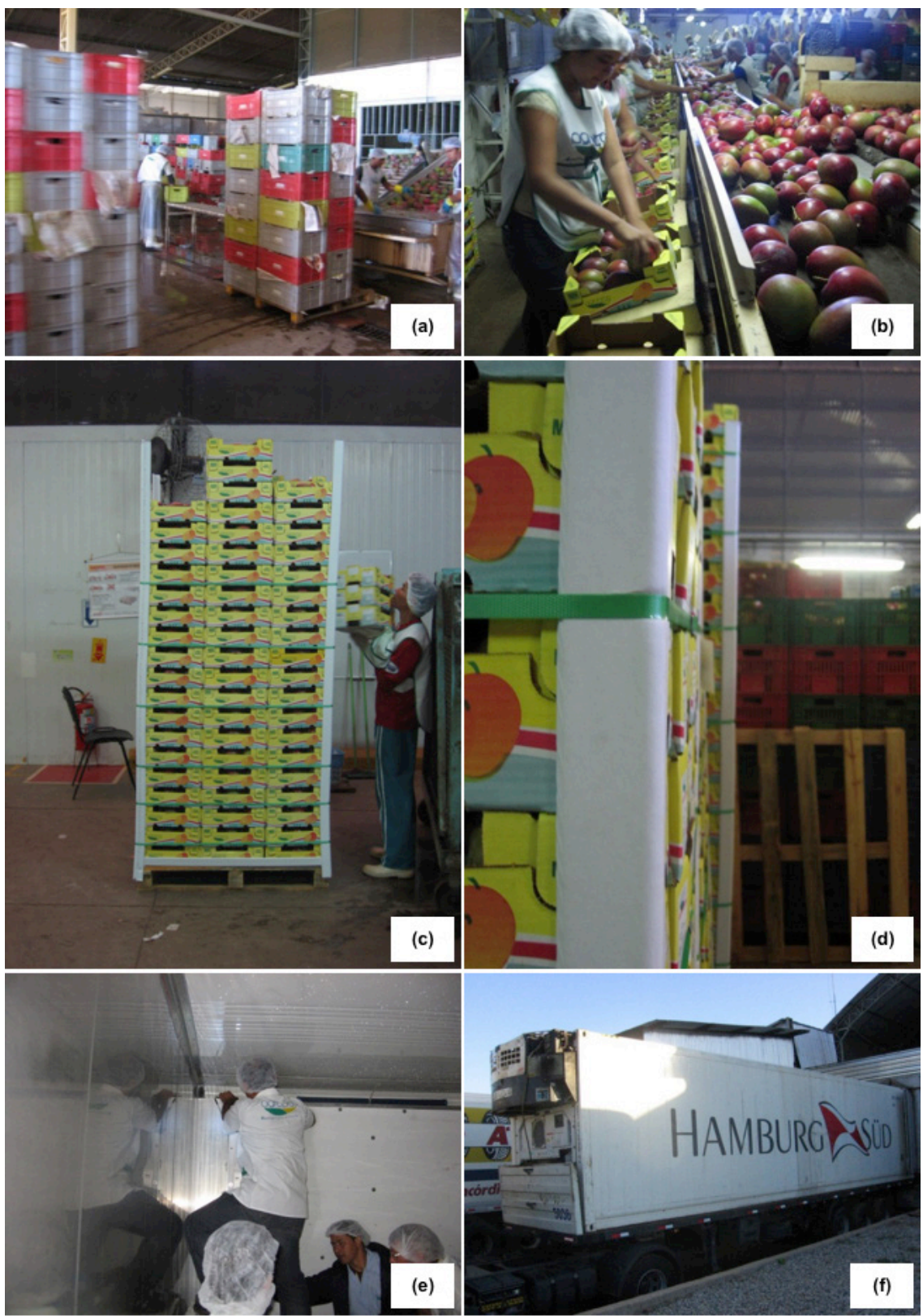

Figure 3. Post-harvest operations in the mango packing house in Petrolina, Brazil

\subsection{Post-harvest and packing operations}

Mango supply chains are similar in Brazil and Peru. As shown in Figure 2 major components of the mango supply chain consisted of growers, packers, exporters, shippers, importers, distributors, retailers and consumers. The mangos were harvested, collected and sent to the packing house. The post-harvest and packing operations in the mango packing houses visited are present in Fig- 
ure 3. Similar to post-harvest operations in Mexico and Guatemala [1], the operations in the Brazilian and Peruvian mango packing houses are fairly automated. Fresh mangos are received in plastic totes in the packing house (Figure 3a). The incoming mangos are washed and graded, sorted by size or weight using manual or automated checkweighers and cameras, and then sent in batches through heat treatment immersion tanks that have chlorinated water. After this post-harvest process in accordance with HACCP practices, the dried mangos are hand packed in trays based on their size, weight and quality (Figure $3 b$ ). The growers and packers, try to meet the primary criteria of a filling a designated $4 \mathrm{~kg}$ tray. Quality standards for mango are available from several sources [3, 4].

The trays are then stacked in a $4 \times 3$, or 12 trays per layer configuration on wooden stringer style pallets, 21 layers high, and unitized using 10-11 horizontal plastic straps with vertical (extruded plastic) corner angle boards (Figures $3 \mathrm{c} \&$ 3d). These are then subjected to either a forced air cooling system, or just placed for longer times in cold air warehouses. Palletized loads are then loaded inside pre-cooled ISO intermodal containers for shipment by truck to the port, and then by ship to the United States, where they are sent to regional distributors (Figures 3e \& 3f).

\subsection{Current mango package systems imported to the U.S.}

Shipments from South America, originating from countries such as Brazil and Peru use doublewall corrugated materials for trays as compared to single wall used to make similar sized and shaped trays coming from Mexico, Guatemala and other Central American nations. While the trays may look similar, the strength required to withstand the longer shipping time from South America, as well as additional cushioning protection, makes the choice of double wall corrugated necessary at the present time. There are new technologies available in United States and Europe that allow for strengthening of single wall corrugated board, but these may not be widely available to countries in Latin America at the present time.

Based on the visit to Brazil, Peru, Mexico and Guatemala [1], the following critical items with reference to the mango shipments are concluded below:

1. The trays used to ship mangos come in a range of different designs and shapes, varying sizes, different quality of wood pallets, all aimed at maximizing and optimizing the shipment in a standard ISO intermodal container or truck trailer. Depending on the tray size, design and corrugated board material there is a variation in compression strength of these trays. Tests were performed to see the differences in performance in compression strength as they impact the stability as well as stack height. Tables 1 and 2 (page 18) show the data collected for these trays from Brazil and Peru.

2. A very small percentage of wood pallets currently being used for mangos are designed to meet US GMA pallet standards.

3. The various designs of trays are either designed with interlocking or nesting tabs, however these features provide very little pallet stability during transit. A strong tray (high compression strength) with bottom sections of the load having more horizontal straps is necessary for long intermodal shipments that include truck and sea voyage. Ideal designs need 10 to 11 horizontal straps and corner posts for long intermodal container shipments from South 
Table 1. Compression strength of sample trays from Brazil

\begin{tabular}{|c|c|c|c|c|c|c|c|c|}
\hline \multicolumn{3}{|c|}{ Sample 1 } & \multicolumn{3}{c|}{ Sample 2 } & \multicolumn{3}{c|}{ Sample 3 } \\
\hline No. & Force (lb.) & $\begin{array}{c}\text { Deflection } \\
\text { (in) }\end{array}$ & No. & Force (lb.) & $\begin{array}{c}\text { Deflection } \\
\text { (in) }\end{array}$ & No. & Force (lb.) & $\begin{array}{c}\text { Deflection } \\
\text { (in) }\end{array}$ \\
\hline 1 & 709.9 & 0.31 & 1 & 750.5 & 0.29 & 1 & 1033.0 & 0.37 \\
\hline 2 & 715.8 & 0.51 & 2 & 621.0 & 0.35 & 2 & 1106.0 & 0.45 \\
\hline 3 & 643.9 & 0.29 & 3 & 922.0 & 0.35 & 3 & 1660.0 & 0.46 \\
\hline Avg. & $\mathbf{6 8 9 . 9}$ & $\mathbf{0 . 3 7}$ & Avg. & $\mathbf{7 6 4 . 5}$ & $\mathbf{0 . 3 3}$ & Avg. & $\mathbf{1 2 6 6 . 3}$ & $\mathbf{0 . 4 3}$ \\
\hline S.D. & $\mathbf{3 9 . 9}$ & $\mathbf{0 . 1 0}$ & S.D. & $\mathbf{1 5 1 . 0}$ & $\mathbf{0 . 0 3}$ & S.D. & $\mathbf{3 4 2 . 9}$ & $\mathbf{0 . 0 5}$ \\
\hline
\end{tabular}

Table 2. Compression strength of sample trays from Peru

\begin{tabular}{|c|c|c|c|c|c|c|c|c|}
\hline \multicolumn{3}{|c|}{ Sample 1 } & \multicolumn{3}{c|}{ Sample 2 } & \multicolumn{3}{c|}{ Sample 3 } \\
\hline No. & Force (lb.) & $\begin{array}{c}\text { Deflection } \\
\text { (in) }\end{array}$ & No. & Force (lb.) & $\begin{array}{c}\text { Deflection } \\
\text { (in) }\end{array}$ & No. & Force (lb.) & $\begin{array}{c}\text { Deflection } \\
\text { (in) }\end{array}$ \\
\hline 1 & 1201 & 0.42 & 1 & 1158 & 0.29 & 1 & 1218 & 0.29 \\
\hline 2 & 115 & 0.21 & 2 & 1256 & 0.27 & 2 & 1427 & 0.28 \\
\hline 3 & 1385 & 0.38 & 3 & 1131 & 0.24 & 3 & 1251 & 0.25 \\
\hline Avg. & $\mathbf{1 2 3 4}$ & $\mathbf{0 . 3 4}$ & Avg. & $\mathbf{1 1 8 2}$ & $\mathbf{0 . 2 7}$ & Avg. & $\mathbf{1 2 9 9}$ & $\mathbf{0 . 2 7}$ \\
\hline S.D. & $\mathbf{1 3 7 . 9}$ & $\mathbf{0 . 1 1}$ & S.D. & $\mathbf{6 5 . 8}$ & $\mathbf{0 . 0 3}$ & S.D. & $\mathbf{1 1 2 . 4}$ & $\mathbf{0 . 0 2}$ \\
\hline
\end{tabular}
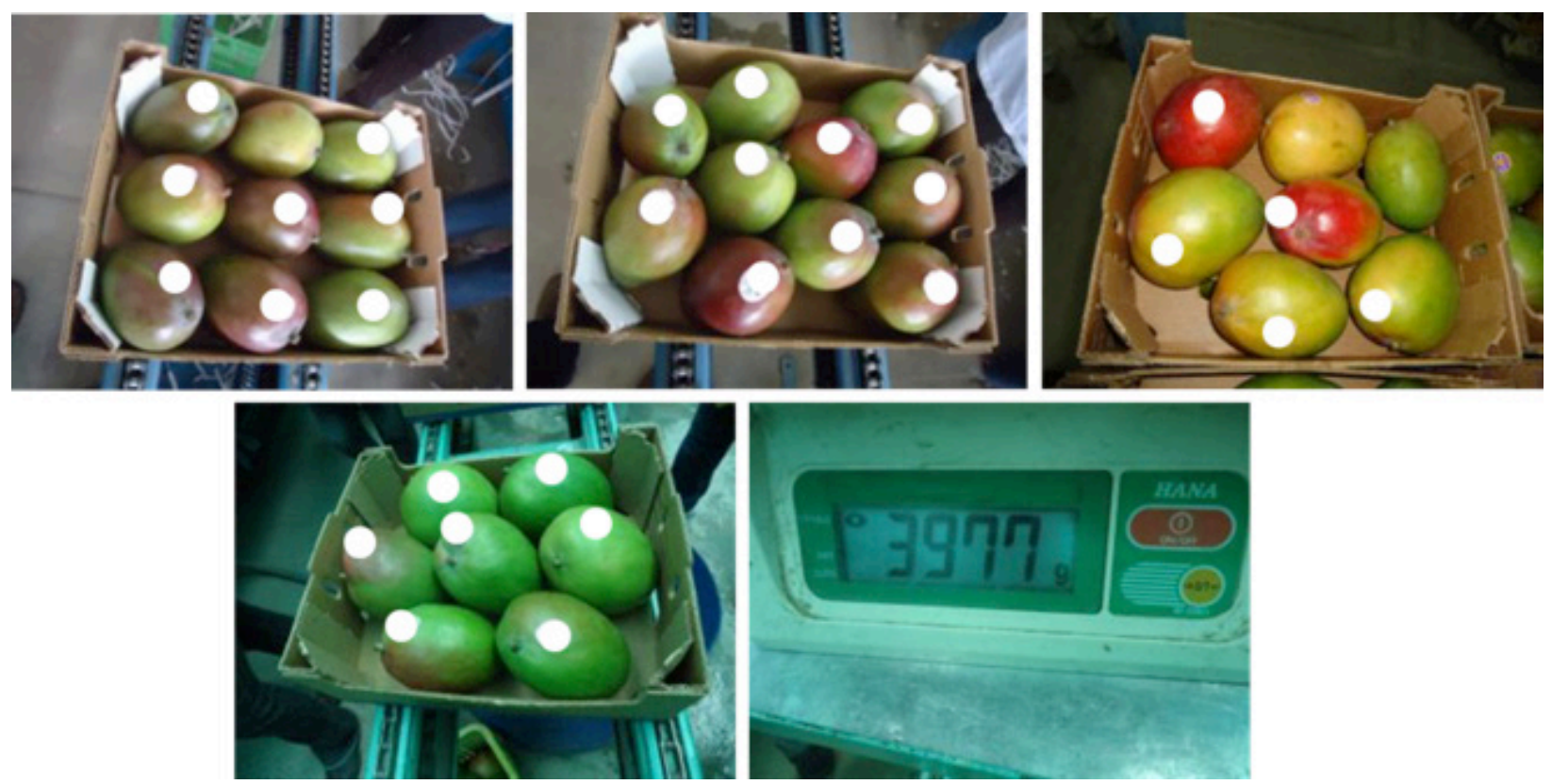

Figure 3. Varying size of mango variety 
America, to 5-7 straps and corner posts for shorter truck shipments from Mexico.

4. The horizontal opening in trays on the sides for cooling is more critical than vertical openings in bottom of the tray i.e., temperature should be lowered and controlled before loading the palletized fruit inside the trailer or ISO container.

5. A $4 \mathrm{~kg}$ tray is impossible to accommodate all varying sizes for the 5 to 18 count fruit (that includes all Keitt, Kent Ataulfo, and Tommy Atkins varieties) (Figure 3) using a $40 \times 48$ GMA footprint. The reason for this is that the 5 count fruit is large and will not meet the 4 $\mathrm{kg}$ requirement, and the $12-18$ count will result in almost $5 \mathrm{~kg}$ of fruit per tray. While the tray may be standardized, the smaller fruit will significantly exceed the tray weight requirement whereas large fruit will not meet weight requirement.

6. A 9 to 12 count tray meeting a minimum $4 \mathrm{~kg}$ is highly likely on a GMA pallet footprint with the previous tray designed, for a $5 \times 3$ tray configuration stacked approximately 21 high.

7. The total number of trays per shipment will go down using a GMA $40 \times 48$ pallet due to the space created in the longitudinal direction as the pallets are loaded into containers in the 40 inch dimension as compared to existing pallets with a 45 inch wide footprint (Figure 4).

8. An alternative is to use a $45 \times 48$ inch pallet, or $45 \times 45$ pallet size similar to the automotive industry that best optimizes both container

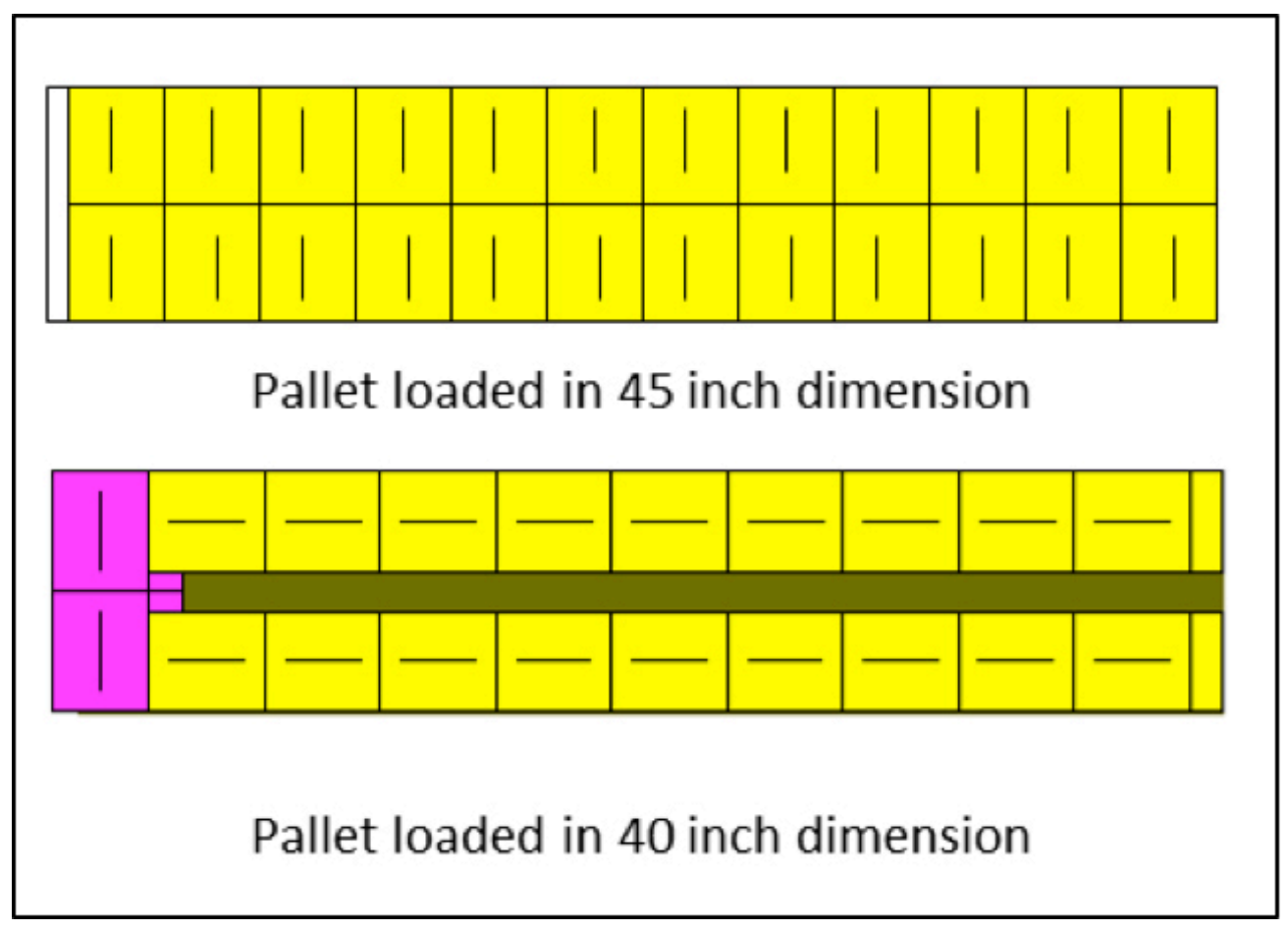

Figure 4. Palletized load of current mango trays on existing 45 inch wide pallet and $40 \times 48$ GMA pallet in a $40 \mathrm{ft}$. container 
and truck shipments with minimum additional blocking and bracing for load stability.

In terms of stack performance by comparing compression strength, the new tray design developed at Michigan State University outperformed the commercially available boxes. It showed higher compression strength (1559.8 1b@0.80 in) than commercially available boxes subjected to compression. Higher compression strength indicated better stack performance of the boxes during storage and distribution. It is also related to

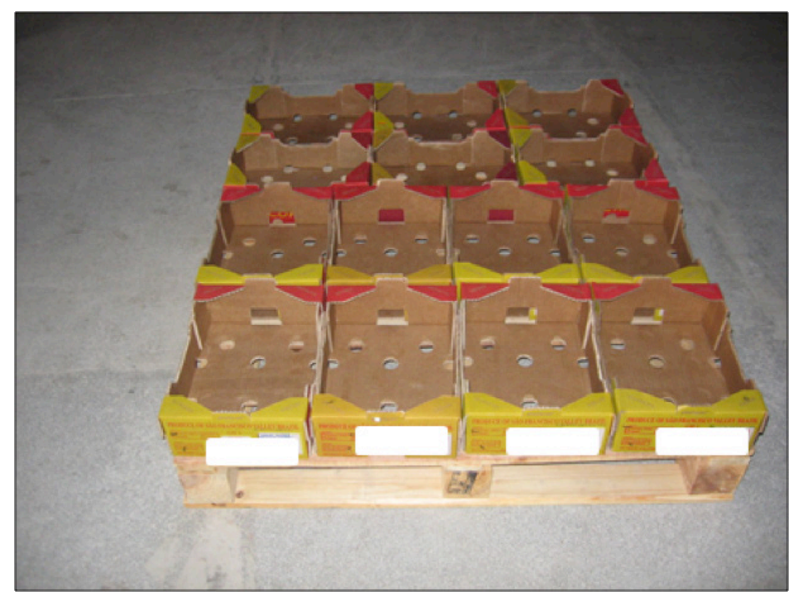

Figure 5. 14 down footprint on a Non-GMA Pallet

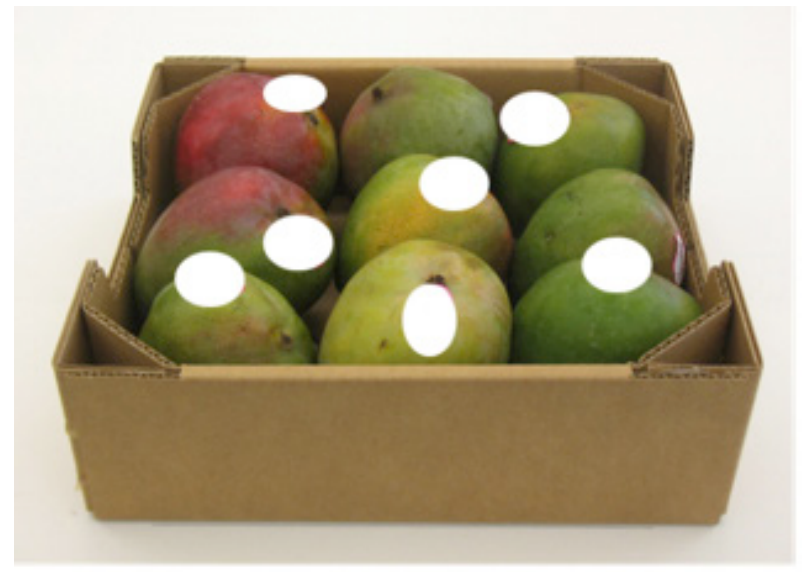

New 12 Down Tray- $5 \mathrm{Kg}$ a protective performance of the boxes for mango shipments. Regarding mango quality, the new designed boxes had the least bruising after vibration test compared to mangos packed in commercially available boxes. The results were in agreement with those previously reported for the current boxes imported from Mexico and Guatemala [1].

In conclusion, the new tray is stronger than the existing mango trays imported to the United States evaluated. This is because of the design feature. In addition, the new tray uses less material, hence reducing cost in a long run and is a sustainable design. It has more opening areas than the existing trays, therefore enhances cooling performance and results in better maintaining the quality of mangos after harvest and during shipping, storage and retail. Comparison of design features between the new and existing trays are summarized in Table 5 (page 22).

\subsection{New mango packaging design}

A recommendation from Brazil was to consider the 14 down pallet configuration shown in Figure 5. While this is feasible for a smaller size fruit and

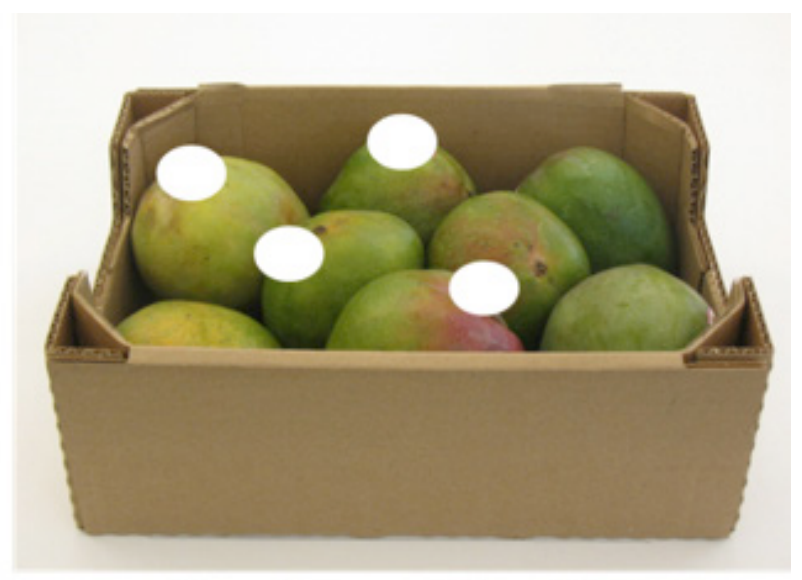

New 15 Down Tray- $3.75 \mathrm{Kg}$

Figure 6. New tray designs for a 12 and 15 down footprint on $40 \times 48$ GMA pallet 
count, it will not permit $4 \mathrm{~kg}$ trays with fruit sizes in the 5-9 count that are widely marketed from Mexico and other Central American suppliers. It also does not allow efficient pre-cooling using forced air facilities, where the venting in the packaging has to align with the air flow direction. The longer shipment time from South America allows for a smaller tray in a 14 down layout to properly cool the fruit and maintain temperature due to the bottom holes and the use of high quality ISO containers that provide vertical air flow.

Based on the findings of the current mango packaging system, two trays designs (Figure 6) were proposed for a $40 \times 48$ standard GMA pallet. The new trays were ascertained the needs for different types of boxes that are currently being imported to the United States. The outside dimension of the 12 and 15 down tray design are 12.875 $\times 11.75 \times 4$ inches and $13.2 \times 9.5 \times 4$ inches respectively. For these tray designs the minimum requirement is a C-flute corrugated board with a 200 psi burst strength was chosen as this was the most commonly available corrugated material available in these countries and by their corrugated suppliers. Therefore using the most widely available flute and material configuration, the cost of paperboard material was kept low. Most of these countries for produce applications have not shifted to the use of ECT board, which does not show better performance in applications of high temperature and humidity that is prevalent in the entire mango supply chain. The maximum allowable numbers of trays that can be palletized to fill a 40 and $53 \mathrm{ft}$. container for both tray designs are shown in Tables $3 \& 4$ respectively.

According to U.S. Department of Transportation, the federal commercial vehicle maximum standards on the interstate highway system [5], a tandem axle truck has a payload weight limit of $34,000 \mathrm{lb}$. of freight. For a $53 \mathrm{ft}$ container the typical payload limit is $56,890 \mathrm{lb}$ [6]. A containerized load for both tray designs in a $40 \mathrm{ft}$. and $53 \mathrm{ft}$. container is shown in Figures $7 \& 8$ (page 28respectively in accordance to the above weight limits.

Table 3. Maximum allowable number of trays in a $40 \mathrm{ft}$. container

\begin{tabular}{|c|c|c|c|c|c|c|}
\hline Footprint & $\begin{array}{c}\text { Wt. Capacity } \\
(\mathbf{K g})\end{array}$ & Layout & $\begin{array}{c}\text { Layers/ Pal- } \\
\text { let }\end{array}$ & $\begin{array}{c}\text { Total No. of } \\
\text { Trays/Pallet }\end{array}$ & $\begin{array}{c}\text { Wt. of Pal- } \\
\text { let Load } \\
\mathbf{( K g})\end{array}$ & $\begin{array}{c}\text { Pallets/40 ft. } \\
\text { Container }\end{array}$ \\
\hline 12 down & 5 & $4 \times 3$ & 12 & 144 & 750 & 20 \\
\hline 15 down & 3.75 & $5 \times 3$ & 13 & 195 & 762 & 20 \\
\hline
\end{tabular}

Table 4. Maximum allowable number of trays in a $53 \mathrm{ft}$. container

\begin{tabular}{|c|c|c|c|c|c|c|}
\hline Footprint & $\begin{array}{c}\text { Wt. Capacity } \\
(\mathbf{K g})\end{array}$ & Layout & $\begin{array}{c}\text { Layers/ Pal- } \\
\text { let }\end{array}$ & $\begin{array}{c}\text { Total No. of } \\
\text { Trays/Pallet }\end{array}$ & $\begin{array}{c}\text { Wt. of Pal- } \\
\text { let Load } \\
\mathbf{( K g})\end{array}$ & $\begin{array}{c}\text { Pallets/40 ft. } \\
\text { Container }\end{array}$ \\
\hline 12 down & 5 & $4 \times 3$ & 12 & 144 & 750 & 46 \\
\hline 15 down & 3.75 & $5 \times 3$ & 12 & 180 & 706 & 46 \\
\hline
\end{tabular}


Table 5. Key design features of the new trays and existing trays currently being used in Brazil and Peru

\begin{tabular}{|c|c|c|c|c|}
\hline No. & Design features & New trays & Current trays & Advantages of new trays \\
\hline 1. & $\begin{array}{l}\text { Corrugated } \\
\text { material }\end{array}$ & Paperboard & Paperboard & - \\
\hline 2. & Flute size & $\mathrm{C}$ & $\begin{array}{l}\text { BC, BE, C, CB, } \\
\mathrm{CC}, \mathrm{CE}, \mathrm{EE}\end{array}$ & $\begin{array}{l}\text { Single wall having same or } \\
\text { higher strength }\end{array}$ \\
\hline 3. & Size, shape & $\begin{array}{l}12 \text { down: } \\
(12.875 \times 11.75 \times 4 \text { in }) \\
15 \text { down: } \\
(13.2 \times 9.5 \times 4 \text { in })\end{array}$ & $\begin{array}{l}\text { Varied, } 12 \text { down } \\
\text { and } 14 \text { down }\end{array}$ & $\begin{array}{l}\text { Standardization to fit } 40 \times \\
48 \text { GMA pallet }\end{array}$ \\
\hline 4. & Tray stacking & $\begin{array}{l}\text { No tabs, provide better } \\
\text { stability }\end{array}$ & $\begin{array}{l}\text { Corner and side } \\
\text { tabs, instability }\end{array}$ & Higher load stability \\
\hline 5. & $\begin{array}{l}\text { Pallet } \\
\text { configuration }\end{array}$ & $\begin{array}{l}12 \text { or } 15 \text { down on } 40 \times \\
48 \text { GMA pallet }\end{array}$ & $\begin{array}{l}14 \text { down on } \\
\text { non-GMA pallet }\end{array}$ & Fit on standard GMA pallet \\
\hline 6. & $\begin{array}{l}\text { Pallet straps, } \\
\text { corner posts }\end{array}$ & Required & Required & $\begin{array}{l}\text { Fit Better and lower height } \\
\text { due to absence of tabs }\end{array}$ \\
\hline 7. & Vent holes & $\begin{array}{l}9 \text { holes on the bottom } \\
\text { face, side cut-outs }\end{array}$ & $\begin{array}{l}\text { Varied on the } \\
\text { bottom/side } \\
\text { faces }\end{array}$ & Better cooling efficiency \\
\hline
\end{tabular}

In addition, the design of the tray should utilize forced air cooling to save energy and reduce time required to pre-cool fruit, and thereby extend the shelf-life. The new boxes with a 12 or 15 down footprint (Figure 6) maximized the opening area in both vertical and horizontal orientation, thus allowed forced air cooling at a reduced time, whereas for the 14 down footprint with a new tray design was not as effective. The improvement in precooling is achieved in the 12 down and 15 down configuration as all the vent holes in the stacked trays are aligned, whereas in a 14 down the trays block the flow of air when placed against each other as shown in Figure 5. In addition the actual available air flow through the bottom is significantly increased in the new design as shown later in this paper. The new tray for a $40 \times 48$ pallet will impact total shipment (Table 3) (12 down: 144/pallet
\& 15 down: 195/pallet) for trade per inter-modal container, and require additional stabilization due to open spaces (Figure 7, page 23).

Vibration and temperature in the intermodal containers were also measured. Figure 9 presents the vibration data from ISO container originating in Petrolina, Brazil to destination Philadelphia, USA. The composite power spectral density from longitudinal, lateral and vertical is shown in Figure 10 (page 24). Average $\mathrm{G}_{\mathrm{rms}}$ values were 0.02 $\mathrm{G}^{2} / \mathrm{Hz}$ (longitudinal), $0.02 \mathrm{G}^{2} / \mathrm{Hz}$ (lateral) and $0.038 \mathrm{G}^{2} / \mathrm{Hz}$ (vertical). Temperature data from the ISO container originating in Petrolina, Brazil to destination Philadelphia, USA are shown in Figure 11. The vibration and temperature data from this study can be used to develop laboratory simulated vibration test to simulate mango shipments from 


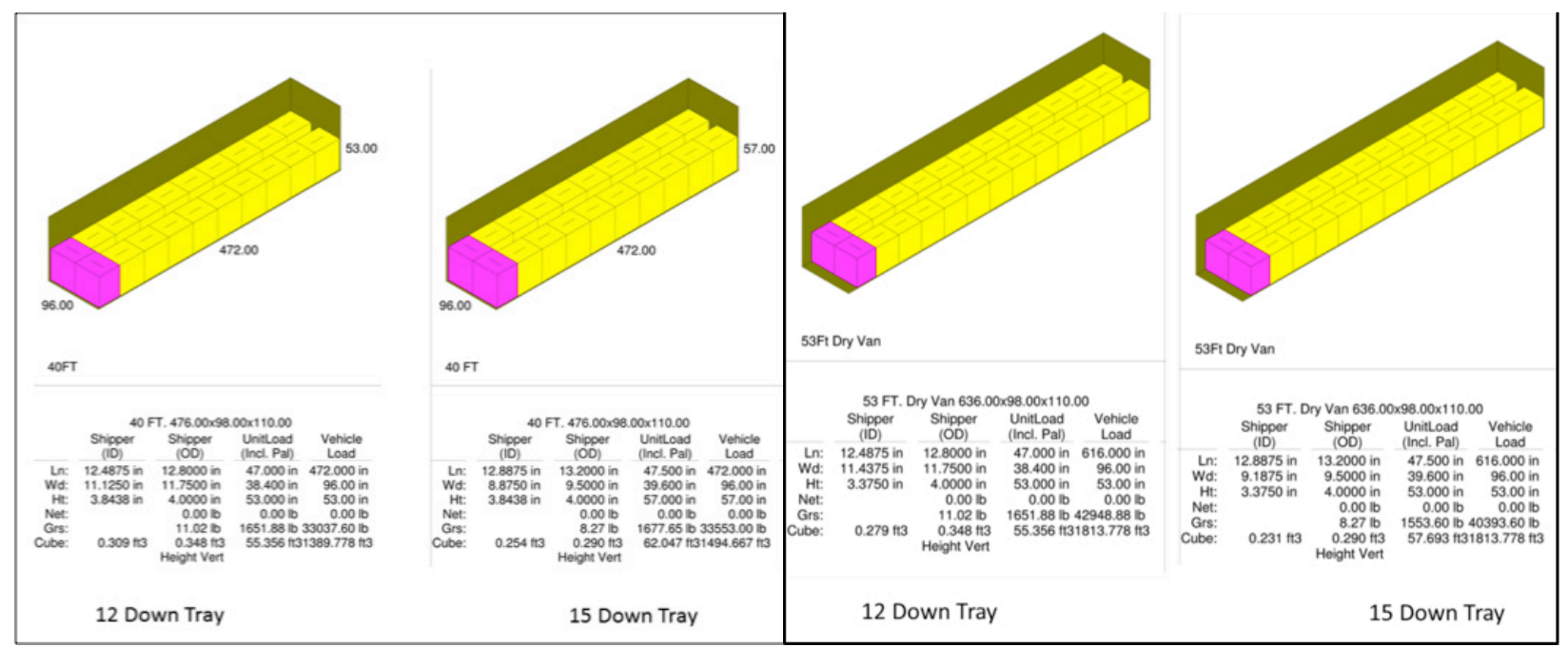

Figure 7. Palletized load of new mango trays in a $40 \mathrm{ft}$. container

Figure 8. Palletized load of new mango trays in a $53 \mathrm{ft}$. container

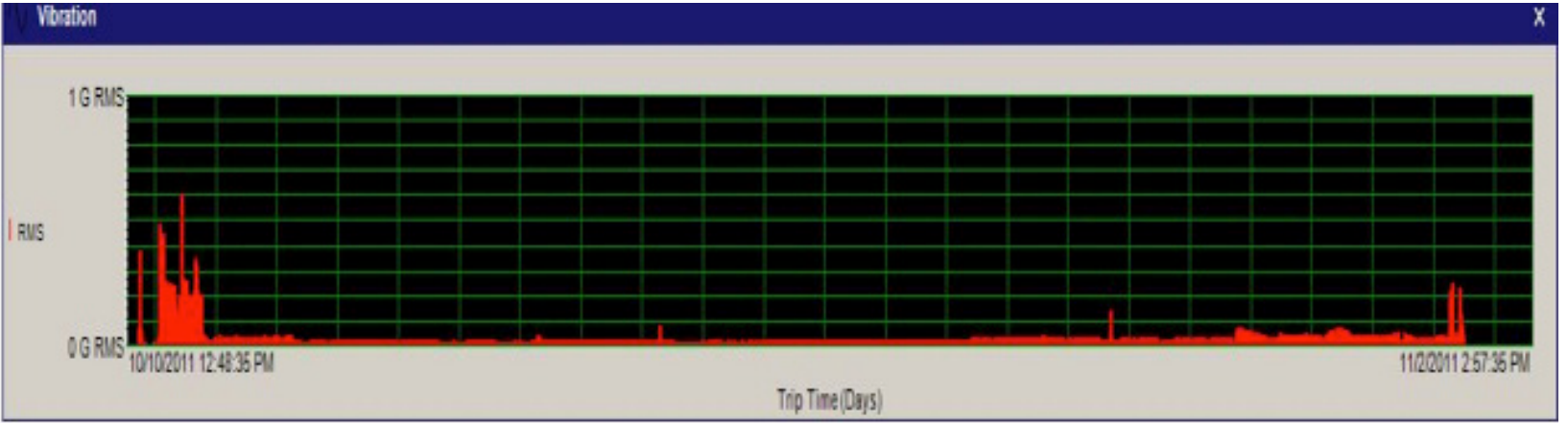

Figure 9. Vibration data from the ISO container originating in Petrolina, Brazil to destination Philadelphia, USA 


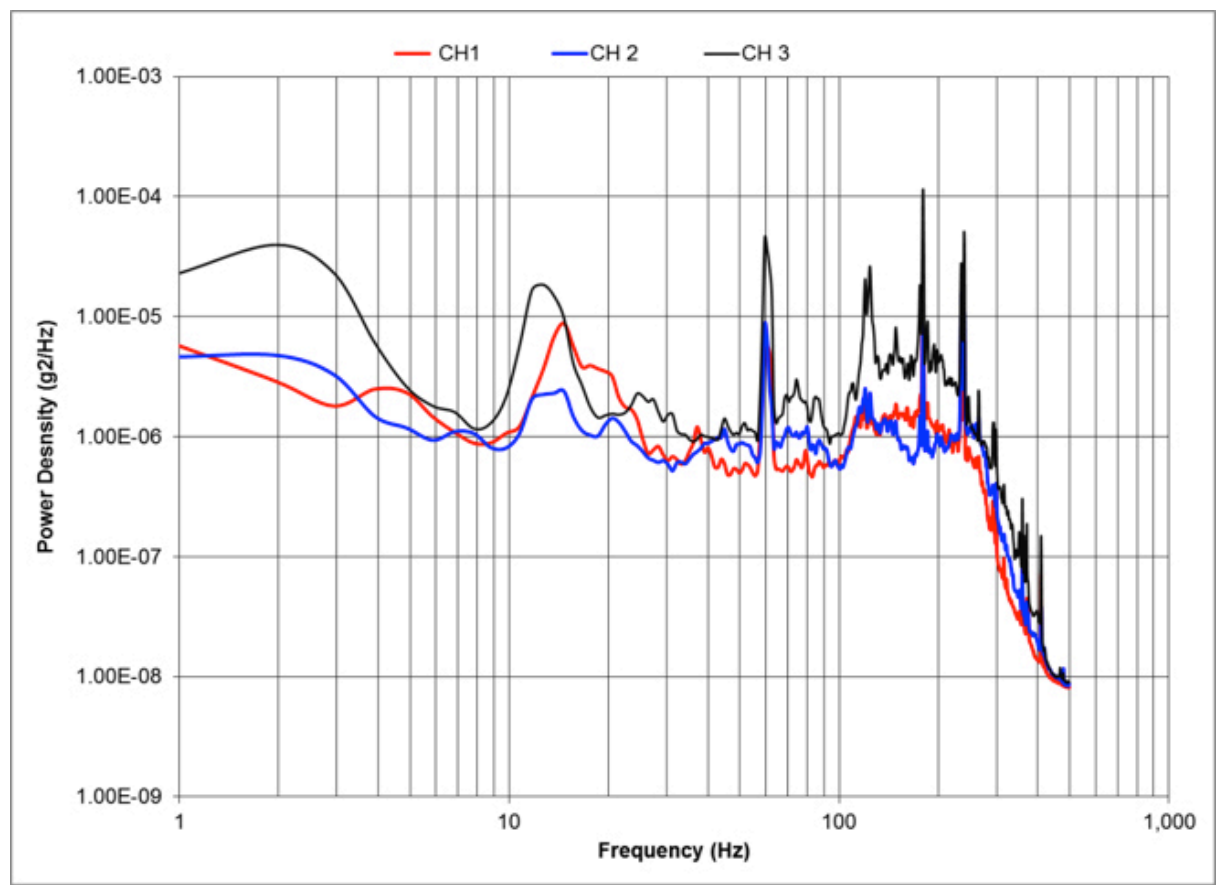

Figure 10. Composite power spectral density* from channel 1 (longitudinal), 2 (lateral) and 3 (vertical) *Average Grms CH $1=0.02 \mathrm{G} 2 / \mathrm{Hz} ; \mathrm{CH} 2=0.02 \mathrm{G} 2 / \mathrm{Hz} ; \mathrm{CH} 3=0.038 \mathrm{G} 2 / \mathrm{Hz}$

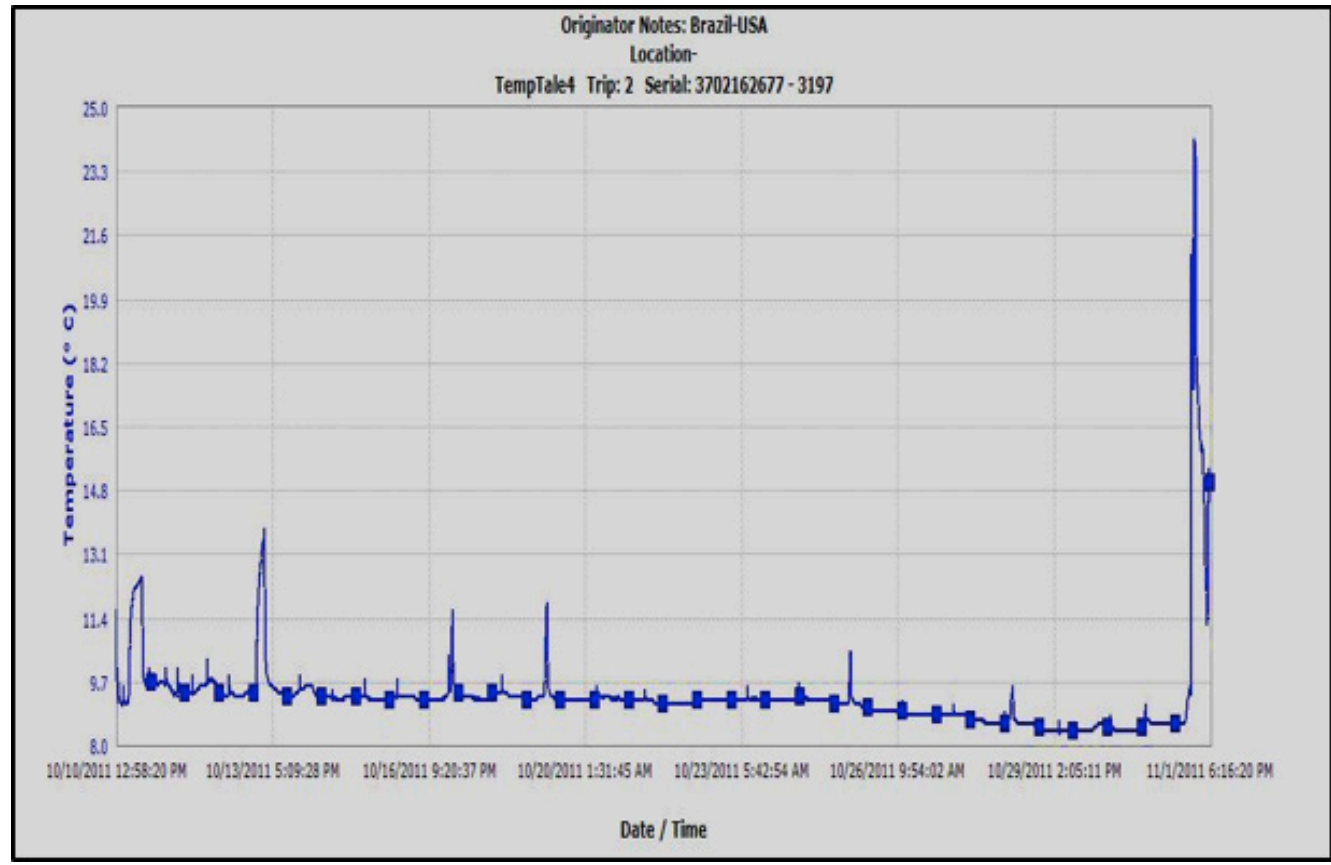

Figure 11. Temperature data from ISO container originating in Petrolina, Brazil to destination Philadelphia, USA 
Central and South America imported to the United States. This pre-shipment test can be used to predict the mango quality after shipment prior to the real-life shipment. Packaging methods can be modified to reduce damage and loss during mango distribution.

By comparing compression strength, the new tray design developed at Michigan State University outperformed the commercially available boxes. It showed higher compression strength (1559.81b@0.80 in) and better resiliency than commercially available boxes subjected to compression. Higher compression strength indicated better stack performance of the boxes dur- ing storage and distribution. It is also related to a protective performance of the boxes for mango shipments. In terms of mango quality, the new designed boxes had the least bruising after vibration test compared to mangos packed in commercially available boxes. The results were similar to those previously reported for the current boxes imported from Mexico and Guatemala [1].

\subsection{Survey of the new packaging design for mango}

A total of 49 out of 88 participants responded to our emails/phone calls, of which 26 agreed to participate in the survey and 23 declined (a few were
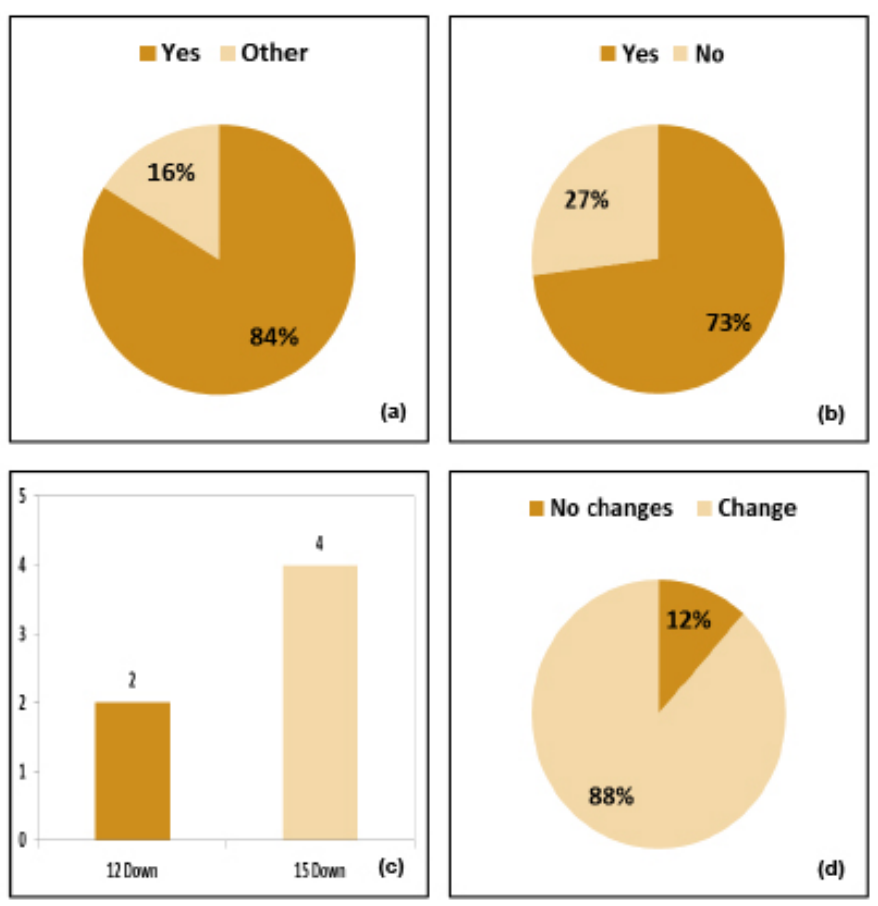

Figure 12. A survey of the retailers and buyers associated with purchasing mango trays in palletized loads in United States

a. Preference for mangos being shipped on a standard GMA $(40 \times 48$ inch $)$ pallet

b. Preference on weight per tray of fruit in a new tray other than $4 \mathrm{~kg}$

c. Average rank of 12 down and 15 down tray (1 is most favorable and 5 is least favorable)

d. Preference for any changes in the pallet or tray size 


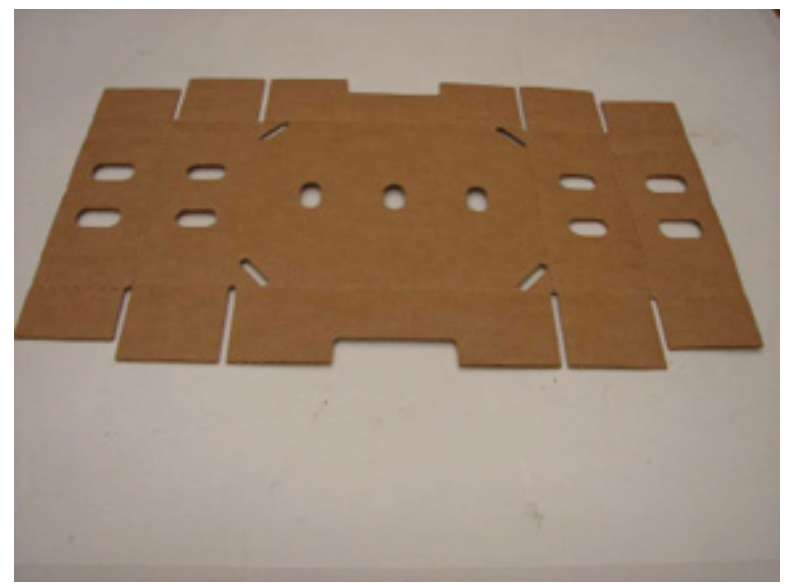

Figure 13: Most Widely Used

Old Mango Tray Design

unreachable due to wrong telephone number). To evaluate the impact on the mango industry of the proposed tray design, a survey of the retailers and buyers associated with purchasing mango trays in palletized loads was conducted. The survey results are shown in Figure 12. As expected the survey results showed that the majority (84\%) of the retailers and buyers contacted preferred mango trays to be shipped on a standard GMA $(40 \times 48$ inch $)$ pallet. About $73 \%$ of the total respondents are willing to consider a new tray design which can hold more than $4 \mathrm{Kg}$ /tray. The respondents further indicated that they prefer the 12 down tray design holding $5 \mathrm{Kg} /$ tray compared to the 15 down tray design holding $3.75 \mathrm{Kg} /$ tray. Only $12 \%$ of the respondents surveyed did not want to make any changes to their current mango tray design.

The survey results are summarized as follows:

1. $84 \%(22 / 26)$ of the respondents preferred mangos being shipped on the standard GMA pallet.

2. $73 \%(19 / 26)$ will consider weight per tray of fruit in a new tray other than $4 \mathrm{~kg}$.

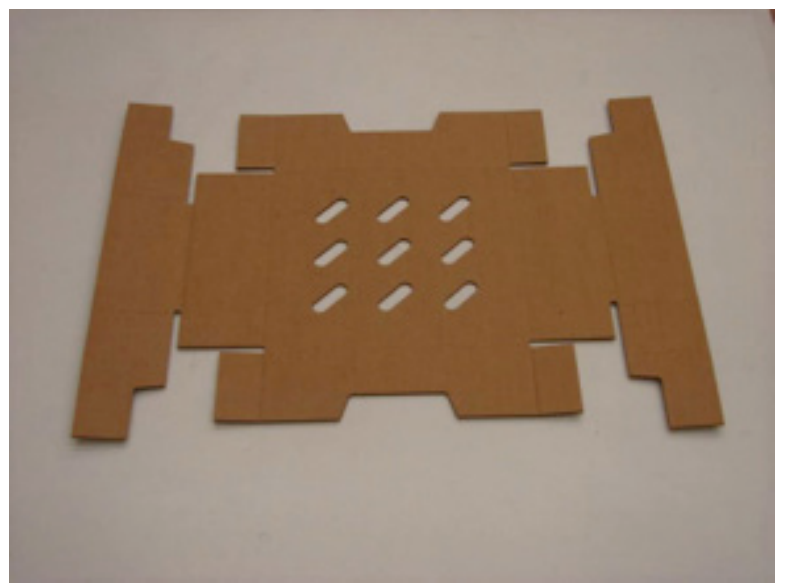

Figure 14: New Tray Design

3. $15 \%$ respondents $(4 / 26)$ preferred either designs

4. $12 \%$ respondents $(3 / 26)$ did not want any changes in the pallet or tray size

Figure 13 shows the most common footprint of a paperboard tray that was being used to import mangos to the United States and Figure 14 shows the new design developed by the researchers of this study. It uses less material attributing to less overall cost and better sustainability. It also offers a three-fold increase in the air flow from the bottom and this enhances the pre-cooling in forced air cooling tunnels as well as in transportation where the cold air moves around the load, as well as from bottom to top. Adding more vents on side walls significantly reduce strength of these trays but using the new design and incorporating more vertical venting and air flow improves cooling efficiencies.

Figure 15 shows the specification of the new mango tray design recommended to the National Mango Board and United States Department of Agriculture. 


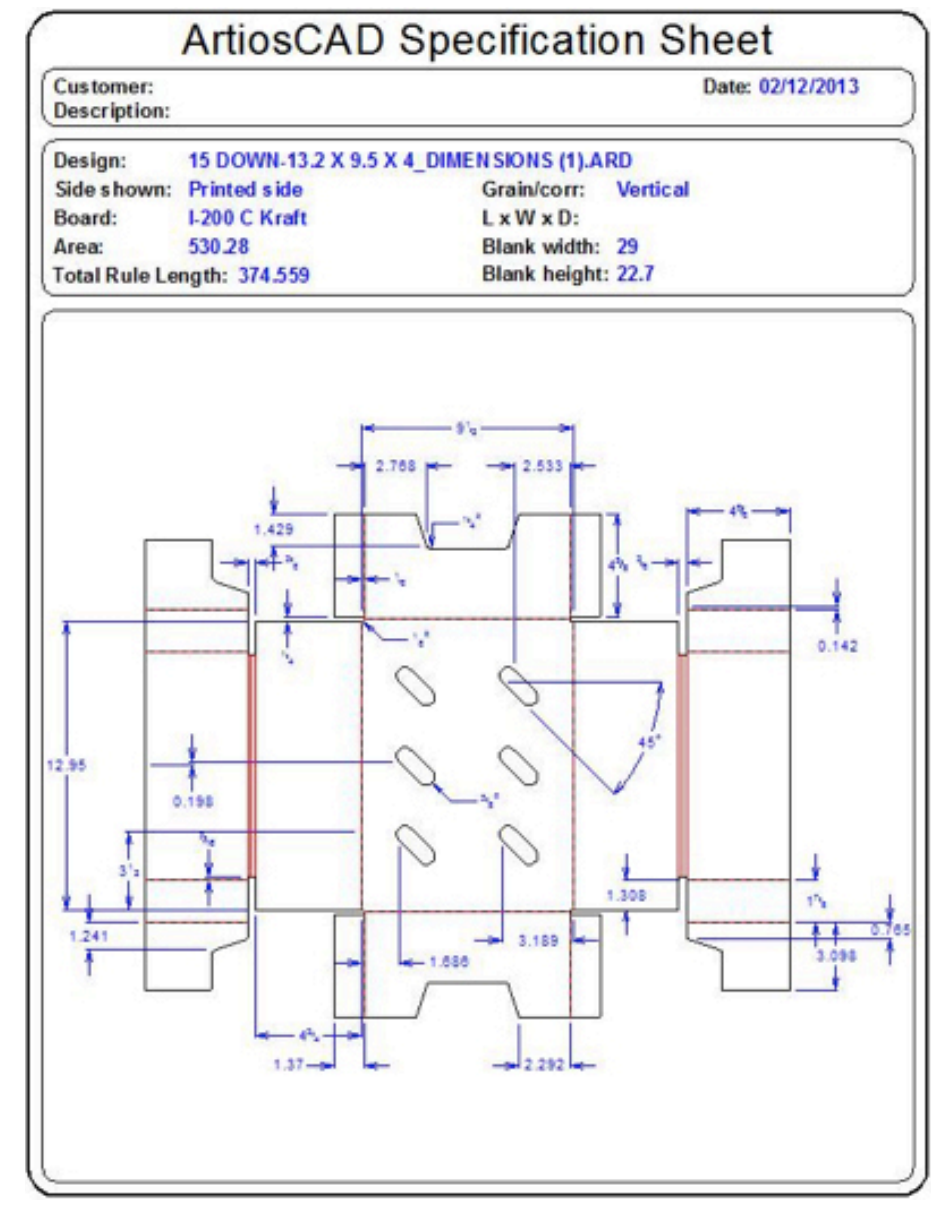

Figure 15: New Mango Tray Design Specification

\section{CONCLUSIONS}

The key findings of this study are provided below:

1. A 14 down common footprint tray does not fit into a $40 \times 48$ GMA pallet and is capable of holding slightly less than $4 \mathrm{~kg}$ of mangos. The cooling efficiency of a 14 down tray is lower than the recommended 12 and 15 down tray. The 12 and 15 down tray dimensions enables a pallet pattern which creates clear cooling channels for a palletized load of mango trays, as compared to a 14 down pallet pattern.
2. Survey results show that the major stakeholders are ready to adopt the proposed mango tray design to accommodate their mango packaging needs. Most packing houses will be capable of erecting the new tray design on their current carton erecting machines. Therefore there will be minimal cost increase in adopting this tray design in their packing facilities

3. Based on the estimated material use of the tray as compared to trays currently being manufactured to ship mangos from Mexico, Guatemala, Peru and Brazil, where manufacturing equipment for corrugated trays 
were also reviewed, there should be no increase in cost of new trays. There may be however one-time equipment setup costs to transition to the new tray configuration. These are likely to range approximately US $\$ 1000$ to $\$ 5000$.

4. A survey on retailers and buyers was conducted to identify the best common footprint and weight of tray that would be acceptable for merchandising mangos in United States.

\section{REFERENCES}

[1] S.P. Singh, K. Saha, V. Chonhenchob, J. Singh, "New Standardized Package System for Imported Fresh Mangos to the United States from Mexico and Guatemala," Proceedings of $19^{\text {th }}$ IAPRI World Conference on Packaging, Melbourne, Australia, June 15 - 18, 2014. Link

[2] ASTM, "ASTM Standards, volume 15.09, Packaging," American Society of Testing and Materials, West Conshohocken, PA, 2002.

[3] R.T. McMillan, D.H. Spalding and W.F. Reeder, "Effectiveness of various postharvest treatments for mango decay control," Proc. Fla. State Hort. Soc., vol. 100, pp. 7-9, 1987. Link

[4] A.A. Kader, N.F. Sommer and M.L. Arpaia, "Postharvest handling systems: Tropical fruits," in Postharvest technology of horticultural crops, A.A. Kader, Ed. Davis: University of California, 2002, pp. 385-398. Link

[5] USDA. 2007. United States Standards for Grades of Mangos. United States Department of Agriculture, Link (Accessed: 8 January 2014).

[6] CODEX. 2005. CODEX Standard for Mangoes. CODEX STAN 184-1993, AMD 1-2005, Link (Accessed: 8 January 2014).

[7] U.S. Department of Transportation, Federal Highway Administration, Link (Accessed: 8 January 2014).

[8] PACER, Link (Accessed: 8 January 2014). 